\title{
Nudges fiscais: a economia comportamental e o aprimoramento da cobrança da dívida ativa
}

\author{
Tax nudges: behavioral economics and improved tax collection
}

\author{
Gustavo Raposo Pereira Feitosa* \\ Antonia Camily Gomes Cruz
}

\section{Resumo}

A partir da constatação da influência de fatores psicológicos e intuitivos na tomada de decisões do ser humano, este artigo explora conceitos da economia comportamental e o "paternalismo libertário" de Cass Sunstein e Richard Thaler, cujas propostas defendem intervenções indutoras de comportamento dos cidadãos por meio de orientações intituladas de nudges. O estudo propõe a aplicação de nudges na cobrança da dívida ativa pela observação de que o comportamento contribuinte é complexo e não se limita ao cálculo do custo e benefício em não cumprir suas obrigações fiscais. Reflete-se sobre a legalidade de a Administração Tributária induzir decisões no papel de "arquiteto de escolhas" em busca do bem-estar social e na resolução de conflitos. Para tanto, investigam-se experiências estrangeiras que evidenciam os benefícios de aplicação de nudges fiscais. Ao final, dispõe-se sobre hipóteses de implementação de estímulos fiscais com potencial arrecadatório, observadas as premissas de diálogo e transparência do Estado Fiscal com o contribuinte.

Palavras-chave: Nudges fiscais. Dívida ativa. Economia comportamental.

\section{Abstract}

Based on the finding that psychological and intuitive factors influence human decision-making, this article explores concepts of behavioral economics and the "libertarian paternalism" of Cass Susntein and Richard Thaler, whose proposals advocate behavior-inducing interventions through nudging guidelines. The study proposes the application of nudges in the collection of tax debt by observing that the contributing behavior is complex and not limited to calculating the cost and benefit of not meeting your tax obligations. Reflects on the legality of the Tax Administration to induce decisions in pursuit of social welfare and conflict resolution. The study investigates foreign experiences with positive results in the application of tax nudges. In the end, it provides on hypotheses of implementation tax incentives with potential revenue based on premises of dialogue and transparency of the Tax State with the taxpayer.

Keywords: Tax nudges. Active debt. Behavioral economics.

\section{Introdução}

O governo do Reino Unido criou, em 2010, um grupo chamado Behavioural Insights Team (BIT), também conhecido como Nudge Unit. A equipe deveria utilizar conhecimentos de áreas como a psicologia e a economia comportamental para orientar a administração na tomada de decisão acerca de políticas

\footnotetext{
Doutor em Ciências Sociais pela Unicamp. Mestre em sociologia pela UFC. Advogado. Professor titular do Programa de pós-graduação em Direito Constitucional da Universidade de Fortaleza - UNIFOR. Professor e coordenador do Mestrado Profissional em Direito e Gestão de Conflitos da UNIFOR. Professor adjunto de Direito Processual Civil da FD-UFC. Líder do grupo de pesquisa JET - Justiça em Transformação. E-mail: gfeitosa@ terra.com.br.

Mestranda em Direito e Gestão de Conflitos pela Universidade de Fortaleza - UNIFOR. Procuradora do Estado do Ceará. Advogada. E-mail: camilycruz@hotmail.com.
} 
públicas e na melhoria dos serviços oferecidos aos cidadãos, entre outros objetivos relacionados à eficiência e à qualidade da gestão.

A experiência inovadora permitia introduzir pequenas mudanças nas práticas administrativas e aferir os impactos de maneira controlada seguindo métodos validados pela ciência. Alguns exemplos dessa inovação acabaram popularizados por meio de estudos em torno das técnicas de nudge,$^{1} \mathrm{com}$ a publicação de livros, artigos e palestras. ${ }^{2}$ As pesquisas e ensaios realizados pelo BIT e por outros grupos existentes em outros países revelaram, por exemplo, que alterações na forma de redação do texto de uma notificação por atraso no recolhimento do tributo podem melhorar a arrecadação.

Os estudos e as intervenções realizadas pelo BIT vêm se difundindo pelo mundo e contribuindo para a afirmação de uma nova forma de lidar com as políticas criadas e implantadas pelos gestores públicos e privados. Trata-se de buscar evidências científicas sobre as melhores práticas e compreender como alcançar ganhos de eficiência e qualidade com alterações inteligentes e bem desenhadas. Essas iniciativas implicam uma profunda quebra de paradigmas, pois exige dos servidores uma abertura constante à reflexão sobre a condução de seu trabalho em áreas como tributação, segurança pública, saúde e educação.

Os resultados observados levam a questionar sobre os potenciais usos dessas experiências no cenário brasileiro. Seria possível utilizar técnicas de nudge em segmentos da administração pública, em especial na esfera tributária? A adaptação das práticas bem-sucedidas do Reino Unido poderia contribuir para a melhoria na eficiência da cobrança de créditos tributários no Brasil? Com base nesses questionamentos, desenhou-se o presente estudo. O artigo contempla uma parte analítica, em que se discutem os conceitos por trás do BIT e sua potencial inserção no quadro normativo do direito tributário nacional, e uma dimensão de intervenção, com o desenho de novas práticas na área da cobrança da dívida ativa.

Pretende-se demonstrar que o Fisco pode se utilizar da técnica de nudge no processo de cobrança de dívida ativa pelo potencial efeito em relação aos perfis de contribuintes. Parte-se da compreensão de que um percentual dos contribuintes se torna devedor ou permanece inadimplente por falta de informação, por aversão à perda financeira ou pela correlação mal dimensionada entre o benefício de se regularizar e o custo de se manter indiferente às obrigações fiscais.

O objeto de investigação do Direito Tributário se ampliou com o fim de explorar o comportamento do contribuinte de ângulos científicos que proporcionem a abordagem do fato jurídico em sua inteireza. O diálogo entre o Direito Tributário e a economia comportamental oferece contributos importantes para entender nuances da decisão do cidadão de cumprir (ou não) com suas obrigações fiscais (MACHADO SEGUNDO, 2018, p. 647).

Com base nos resultados encontrados pela economia comportamental, adota-se como hipótese que a conduta do contribuinte de não cumprir obrigações fiscais ou se manter inadimplente com o Fisco nem sempre tem origem numa decisão deliberada e racional em que se analisa estatisticamente o custo benefício de não cumprir com o seu dever fundamental de pagar tributo.

A importância deste artigo, que recorre aos conhecimentos desenvolvidos pelo BIT, com base na economia comportamental e na neurociência, decorre da necessidade de se propor intervenções jurídicas eficazes e resolutivas na relação entre o Fisco e o contribuinte. Afinal, se o Direito é uma ciência que regulamenta a conduta humana, é relevante aprimorar o conhecimento sobre a mente humana. Investigar a lógica da tomada de decisão dos cidadãos contribui para a implementação de um Direito Tributário com aderência à realidade.

O termo nudge significa literalmente "cutucar" ou tocar alguém para chamar atenção para algo. A ideia central das técnicas de nudge consiste, de maneira sintética, em estimular, induzir ou impulsionar comportamentos a partir de mudanças nas formas como se lida tradicionalmente com certos problemas. O tema será mais bem abordado ao longo do artigo.

A popularização do conceito de nudge deve-se, em grande medida, ao livro escrito por Richard Thales e Cass Sustein (2019), intitulado "Nudge: Como tomar melhores decisões sobre saúde, dinheiro e felicidade". Não obstante, há um grande número de relatos de experiências e artigos científicos que tratam do assunto. Para uma visão panorâmica sobre o assunto, recomenda-se a leitura dos relatórios anuais do The Behavioural Insights Team (2018) e a visita ao seu portal eletrônico (Disponível em: https://www.bi.team/about-us/. Acesso em: 21 nov. 2019 ). Existem grupos de $\mathrm{BI}$ em funcionamento em algumas das principais universidades do mundo, como em Harvard, Oxford e Cambridge. 


\section{Perspectivas da economia comportamental: seriam as escolhas do contribuinte racionais?}

Os fatores que impulsionam o interesse do contribuinte em pagar tributos extrapolam o cálculo racional do custo e benefício atribuído ao Homo economicus. ${ }^{3}$ Em contraposição aos economistas clássicos, a teoria da economia comportamental amplia as hipóteses que influenciam a tomada de decisão do homem, que vai além de uma racionalidade calculada. ${ }^{4}$

A teoria econômica comportamental ${ }^{5}$ ganhou notoriedade a partir da década de 1970, com os resultados obtidos em experimentos por Amos Tversky e Daniel Kahneman ${ }^{6}$, psicólogos israelenses que buscavam respostas sobre condutas comportamentais que extrapolavam o padrão supostamente racional e lógico difundido pela economia clássica.

A pesquisa dos cientistas contestou a racionalidade de escolha atribuída aos indivíduos e os resultados atestaram que outras variáveis compõem a escolha demonstrada. Demonstrou-se que, no processo de tomada de decisão humana, a racionalidade é limitada por fatores psicológicos, associações emotivas (vieses de intuição) (KAHNEMAN, 2012, p. 10) e suposições mentais automatizadas que distorcem a estatística da realidade de modo que os sujeitos nem sempre são aptos a escolher a melhor decisão para si (KAHNEMAN; TVERSKY, 1974, p. 1124-1131).

O movimento acadêmico iniciado na área da Psicologia, desbravador de conceitos ortodoxos econômicos, foi sucedido pelo economista norte-americano Richard Thaler, ${ }^{7}$ cujas contribuições expandiram uma perspectiva de humanização da ciência econômica.

Thaler (2015) reconhece a relevância das premissas de otimização na tomada de decisão defendida pelos economistas clássicos, mas critica a tentativa de avaliar o ser humano - Homo sapiens - como uma criatura fictícia conceituada de Homo economicus, que o professor denomina de "Econ". "Econs" consistem em seres frios, calculistas, que não erram. ${ }^{8}$ No entanto, sociedades compõem-se de humanos que incorrem em vários desvios, daí a necessidade de uma abordagem mais humana e realista da economia (THALER, 2015, p. 2).

Contudo, a legislação tributária volta-se, na maioria dos seus dispositivos, ao homem econômico, aquele contribuinte que considera, na sua decisão, apenas os custos e benefícios de honrar com suas dívidas fiscais. Considera-se que, quanto maior for o risco de ser auditado pelos agentes fiscais e a severidade da punição, maior será o estímulo para o contribuinte pagar seus impostos (ALLINGHAM; SANDMO, 1972, p. 323-338).

Observa-se que a análise do contribuinte se baseia no "paradigma do crime" à medida que se investe no medo, na sanção pela imposição de multas elevadas pelo descumprimento de suas obrigações fiscais, ou na política de conceder prêmios ou castigos, a depender da conduta do cidadão, reforçando a premissa racional de perda versus ganho. ${ }^{9}$

\footnotetext{
O conceito de Homo economicus é atribuído à Escola clássica da Economia que tem como precursor Adam Smith que atribui exclusivamente à racionalidade a forma de escolha dos indivíduos pela constante que considera o máximo de benefício da decisão para preservar interesse próprio.

4 Samuel Bowles sugere que o homem econômico clássico só é interessante na sala de aula, porque o que se nota na sociedade é uma valorização além de uma conduta individualista e racional (BOWLES, 2016, p. 34).

5 Behavioral Law and Economics tornou-se uma nova disciplina acadêmica da Economia ofertada inicialmente pela Universidade da Pensilvânia em 2010 (RIBEIRO; DOMINGUES, 2018, p. 466).

6 Consolida-se uma mudança de paradigma científico na Economia quando o Prêmio Nobel de Economia de 2002 foi concedido a um professor de outro ramo, no caso, o psicólogo Daniel Kahneman. Tversky não recebeu o prêmio porque faleceu em 1996. (FOX, 2015, p. 63-70).

Thaler foi agraciado com o prêmio Nobel de Economia de 2017.

8 "Se você ler teóricos de economia, vai descobrir que o Homo economicus pode pensar como Albert Eisnstein, ter tanta memória quanto um supercomputador e ter tanta força de vontade quanto Mahatma Gandhi. Mas pessoas que conhecemos não são assim. Pessoas reais têm dificuldade de fazer divisões complexas sem calculadora, às vezes esquecem o aniversário do parceiro e ficam de ressaca no Ano- Novo. Esses não são Homo economicus; são Homo sapiens" (THALER; SUNSTEIN, 2019, p. 15).

9 Machado Segundo (2018, p. 648) também constata que a previsão de tributos extrafiscais na legislação por meios dos quais se estimula ou desestimula condutas com mais ou menos ônus tributários é resultado da visão do contribuinte como um Homo economicus.
} 
A título de exemplo, na legislação federal e nas estaduais, constatava-se a previsão de multas punitivas que chegavam a duzentos por cento da obrigação principal. Somente em 2015, no Recurso Extraordinário n. ${ }^{\circ}$ 833.106, o Supremo Tribunal Federal (STF) determinou que as penalidades não pudessem ultrapassar o limite de cem por cento da obrigação principal. A visão mais humanizada da economia comportamental contribuiu para novas percepções da governança tributária.

Esse contexto de "paradigma do crime" foi superado, aos poucos, nas Administrações Tributárias mais avançadas, havendo a análise da conduta do contribuinte sob o "paradigma do serviço", ${ }^{10}$ em que o enforcement ${ }^{11}$ do Estado tem relevância, mas em conjunto com medidas que contribuam para uma relação cooperativa e de mais confiabilidade entre o Fisco e o cidadão. ${ }^{12}$

Se o comportamento do contribuinte pode ser aleatório e motivado instintivamente, não se pode padronizar a conduta unicamente como racional. Logo, as políticas públicas que tratam o contribuinte com base num perfil único e predisposto à sonegação não se mostram eficientes.

James Alm, professor do departamento de economia da Universidade da Georgia, tem relevante pesquisa sobre o cumprimento de obrigações fiscais em países da América Latina e Caribe. Seu estudo, escrito com Martinez-Vazquez, atestou que o comportamento dos contribuintes não se justifica inteiramente por elementos de ordem financeira, mesmo nos países que possuem baixo índice de cumprimento de obrigações tributárias (ALM; MARTINEZ-VAZQUEZ, 2007, p. 15).

Alm e Martinez-Vazquez (2007, p. 49) constataram outras variáveis do comportamento do contribuinte além da intimidação, como a influência social, a confiança no governo e a razoabilidade de suas exigências, bem como a sensação de serem adequadamente tratados por autoridades estatais e que suas opiniões são consideradas, mesmo que, ao final, não sejam atendidos. Os autores concluem que qualquer abordagem voltada ao cumprimento das obrigações tributárias deve considerar todo o conjunto de comportamentos relevantes para guiar as políticas que asseguram o cumprimento da lei (ALM; MARTINEZ-VAZQUEZ, 2007, p. 56).

A esse respeito, recente estudo da Organização para a Cooperação e Desenvolvimento Econômico (OCDE) reforça elementos da economia comportamental e recomenda às administrações fiscais que formulem suas políticas fiscais considerando os diferentes perfis de contribuintes para, por exemplo, não desestimular aqueles que cumprem suas obrigações independentemente de ameaça. ${ }^{13} \mathrm{O}$ estudo não diminui a importância das auditorias e da fiscalização, mas recomenda que sejam direcionadas somente aos contribuintes com potencial sonegador. Para isso, a tecnologia deve auxiliar na análise prévia das condutas dos cidadãos.

A organização ressalta que "small changes in the taxpayer's environment can have a big impact on behaviour" (OECD, 2014, p. 18). ${ }^{14}$ É nesse ambiente que prospera o conceito de nudge difundido por Cass Sunstein ${ }^{15}$ e Richard Thaler, considerado um mecanismo promissor com potencial de influenciar as decisões dos cidadãos, a baixo custo, mas sem interferir na consciência da liberdade de escolher do agente econômico. ${ }^{16}$

10 Richard Bird (2010, p. 4), professor da Universidade de Toronto e consultor de reformas tributárias em vários países, defende que "The key administrative problems are then identifying and controlling taxpayers and catching those who cheat. These tasks are indeed important, and this emphasis is understandable in a country undergoing rapid transition, but problems of tax enforcement cannot be solved simply by calling in the 'tax police.' Extensive research in a number of countries shows that there is much to be gained from viewing taxpayers more as clients- perhaps not very willing clients, but still clients—-than as would be criminals."

11 Refere-se à força de aplicação das normas.

12 Bird (2010, p. 4) refuta os resultados matemáticos da teoria dos jogos ao defender que a relação do Fisco com o contribuinte não é um jogo de aposta ou o dilema do prisioneiro "Taxpayers do not always view the decision to pay or not as a simple gamble. Some always pay; some always cheat; and some cheat when they think they can get away with it."

13 De fato, "the best compliance strategies choose the most appropriate intervention for the risk or opportunity, rather than utilising one approach for all." (OECD, 2014, p. 19).

14 Tradução livre: "pequenas mudanças no ambiente do contribuinte podem ter grande impacto no comportamento".

15 Cass Sunstein é professor, fundador e diretor do Programa de Economia Comportamental e Políticas Públicas da Harvard Law School, e participou de setores estratégicos da Casa Blanca no governo de Barack Hussein Obama. Disponível em: https://hls.harvard.edu/faculty/directory/10871/ Sunstein. Em 2008, escreveu, com Richard Thaler, o livro Nudge: improving decisions about health, wealth and hapiness, que expandiu o termo nudge.

16 Ressalte-se que a tecnologia pode alterar o contexto da análise da tomada de decisão já que as escolhas estão sendo cada vez mais transferidas de pessoas para máquinas, que não estão sujeitos aos mesmos vieses ou limites de processamento de informações que os humanos enfrentam. Sobre isso, sugere-se Fox (2015, p. 70). Harari $(2018$, p.80) vai além e afirma que governos poderão hackear a tomada de decisão de humanos por meio de algoritmos de big data, mais confiáveis do que a mente humana, o que possibilitará a manipulação guiada com precisão. 


\section{O paternalismo libertário de Sunstein e Thaler: o "cobrador de impostos" arquitetando escolhas?}

Nudge, ou nudging, é um termo da língua inglesa que significa "cutucar", tocar levemente para chamar atenção ou dar um empurrão. Consiste numa indicação, numa ferramenta meramente sugestiva que influencia a tomada de decisões dos indivíduos para o incremento de objetivos específicos nos mais diversos setores, públicos ou privados.

A medida parte da premissa econômica comportamental de que os cidadãos nem sempre escolhem as melhores opções para si (racionalidade limitada) porque suas decisões sofrem influência de vários fatores, por vezes destoantes da realidade material e do que realmente lhes é benéfico. Se o comportamento humano irracional pode ser previsto, poderá ser influenciado ou estimulado.

Sunstein e Thaler (2019, p. 13-14) defendem a implementação de nudges nas políticas públicas por meio de intervenções suaves na decisão dos indivíduos. Por se tratar de uma ação que intervêm em processos decisórios, deve haver uma atenção redobrada sobre a vontade do cidadão de modo a garantir que o agente influenciador (responsável pelo nudge) encontra-se, realmente, na busca do bem-estar social. Somente com este tipo de cuidado, considera-se essa intervenção legítima.

Os autores justificam a intervenção de um Estado Regulador no papel de maximizar a qualidade de vida dos cidadãos e conceituam de paternalismo libertário o movimento que admite a ideia de influenciar o comportamento das pessoas para fazerem determinadas escolhas, sem excluir a consciência dessas decisões, ou seja, "não se pretende um Estado maior, mas sim, um governo melhor" (SUNSTEIN; THALER, 2019, p.23). A contradição do termo invoca um meio de influenciar o comportamento dos indivíduos - que mantém o livre arbítrio de suas escolhas -, mas sem se mostrar intrusivo e sem recorrer a proibições ou à ordem (SUNSTEIN; THALER, 2019, p. 13-14).

A terminologia "libertária" contrapõe o conceito intrusivo da palavra paternalismo exatamente para ressaltar que um dos pilares na utilização de técnicas de nudges é o respeito à liberdade de escolha, desde que haja transparência e publicidade na forma de expor as opções ao cidadão.

O "soft paternalismo" permitiria aos cidadãos tomar decisões mais eficientes, com maior disponibilidade de informações e com menor probabilidade de tomarem decisões influenciadas por vieses cognitivos equivocados. A ideia é deixar evidentes os elementos relevantes para decisão no contexto das possibilidades apresentadas ao cidadão (SUNSTEIN, 2012, p. 163), porque alguns indivíduos, quando têm fácil acesso às informações ${ }^{17}$ e são bem esclarecidos sobre escolhas pelo Estado, tendem a colaborar com o bem-estar social (KOROBKIN; ULEN, 2000, p. 1138-1144).

Recomenda-se que o Estado exerça a função de um "arquiteto de escolha", que se desenhe orientações que possam estimular o bem-estar social. De uma forma geral, consideram-se viáveis "programas que contemplem mecanismos indutivos de comportamento, como disposição de informações em ordem de interesse, incentivos comportamentais com ou sem contrapartida financeira para a tomada de decisões" (RIBEIRO; DOMINGUES, 2018, p. 467).

O paternalismo libertário de Sunstein e Thaler não escapa às críticas de estudiosos ${ }^{18}$. Os antipaternalistas temem que o Estado ultrapasse os limites da finalidade educativa e preventiva das técnicas de nudge ao ponto de manipular e coagir os cidadãos a decidirem com base em interesses escusos.

A opção por designar seu trabalho de paternalismo libertário remete a um debate mais profundo e longo sobre liberalismo, socialismo e os limites da intervenção estatal. Tal debate político é importante, mas pode desviar a atenção de uma ampla gama de estudos sobre o comportamento humano que guiam

17 Sunstein (2015, p. 437) afirma que alguns nudges, inclusive, promovem a autonomia dos cidadãos de decidir porque uma decisão não poder ser considera autônoma se baseada na falta de informação e exemplifica: "If someone takes a stomach medicine in the belief that it will help with a cold, there is no interference with autonomy in informing him that it is stomach medicine".

18 Andrew Fergusin (2010) redigiu artigo em que refuta os resultados da economia comportamental e sua importância no governo de Barack Obama. "Actually, it's the study of college kids in psych labs. We change and adapt over the course of months and years, reflect and learn, and call on the help of friends and family. These vital and unpredictable improvisations won't happen in the vacuum of the college psych lab, with a besmocked Ph.D. student hovering close by. Actually, it's the study of college kids in psych labs.". 
as técnicas de nudge e as pesquisas dos Behavioural Insights Teams. Para além da discussão sobre os projetos de sociedade e de economia, consolida-se, a partir da economia comportamental, um conjunto de conhecimentos sobre o aprimoramento das políticas públicas, a qualificação da gestão governamental e a melhoria dos serviços ao cidadão.

A pretexto do risco de uma intervenção excessiva, críticos concluem que o melhor caminho é não arriscar, mesmo reconhecendo a credibilidade dos resultados obtidos com a pesquisa. Machado Segundo (2018, p. 654), embora reconheça a evidência dos resultados obtidos com a psicologia e economia comportamental, reforçando, inclusive, que não devem ser desprezados pelo Direito Tributário, conclui que a aplicação dos resultados não deve ocorrer às cegas, especialmente quando nudges são aplicados por meio de concessão de incentivos e restrições, "sendo preferível a não intervenção àquela capaz de causar efeito colateral pior que a doença" (MACHADO SEGUNDO, 2018, p. 656).

Sunstein e Thaler (2019, p. 243), no entanto, rebatem as críticas que se baseiam exclusivamente no medo ao justificar que a existência do risco por si só não pode ser obstáculo para a implementação da ideia, embora admitam que as técnicas de nudges podem ser aprimoradas. Além disso, admitem a necessidade de aprimoramento e da adoção de todas as ferramentas que possam minimizar o desvirtuamento da técnica pelo governo.

Reforça o argumento acima a constatação, ao final, de que não há escolha sem contexto e que, de alguma forma, invisível ou visível, sempre haverá intervenção do Estado na tomada de decisão dos cidadãos, exatamente porque cabe a este organizar politicamente e juridicamente a sociedade. ${ }^{19}$ É impossível ser neutro, porque "da mesma forma que não existe edifício sem arquitetura, não existe escolha sem contexto" (SUNSTEIN; THALER, 2019, p. 244).

Os autores relatam que a inserção de elementos psicólogos na análise do comportamento humano recebe críticas dos economistas clássicos porque estes entendem que os efeitos são limitados a situações mais simples e em relação a pessoas mais desinformadas. No entanto, Sunstein e Thaler (2019, p. 90) rebatem o menosprezo pela ausência de prova científica, porque, se as escolhas se mostrassem melhores para assuntos importantes, "o homem econômico" não se divorciaria e estaria sempre seguro da faculdade que pretende cursar.

O estudo do comportamento humano tem subsidiado a elaboração de políticas públicas em vários países. A primeira iniciativa governamental foi criada em 2010, no Reino Unido. O Behavioural Insights Team (BIT) teve por fim propor políticas públicas de baixo custo que permitissem aos cidadãos fazerem melhores escolhas para si mesmos.

Em relatório publicado no início de 2017, a Organização para a Cooperação e Desenvolvimento Econômico (2017, p. 4) analisou 60 iniciativas em 23 países e concluiu que os nudges já são rotineiramente utilizados em inúmeros órgãos públicos, em diversas áreas, e têm potencial para melhorar a relação entre as instituições públicas e o cidadão. O estudo esclarece a necessidade de obter dados confiáveis para se aplicar os insights e se tornar uma ferramenta pública robusta, além do dever do governo de publicar e compartilhar os resultados.

No entanto, admitir que o Estado Fiscal possa se utilizar de técnicas indutoras de cobrança pode parecer uma aventura perigosa, especialmente quando a legislação tributária se revela essencialmente opressora e a distinção entre técnicas de nudge e medidas de coação e manipulação ainda não estão bem definidas.

Kahneman (2012, p. 29) justificaria a rejeição impulsiva da proposta pela heurística da disponibilidade, ${ }^{20}$ porque "as pessoas tendem a estimar a importância relativa das questões pela facilidade com que são puxadas da memória - e isso é amplamente determinado pela extensão da cobertura na mídia." Assim, automaticamente, nossa memória mais recente se remete a um Estado Fiscal potencialmente corrupto e que visa à arrecadação a qualquer custo.

19 Constituem objetivos fundamentais da República Federativa do Brasil organizar a sociedade de forma a promover o bem comum, conforme previsto no artigo $3^{\circ}$ da Constituição da República Federativa do Brasil.

20 Viés que influencia na tomada de decisões e contribui para escolhas não necessariamente racionais (KAHNEMAN, 2012, p. 16). 
Portanto, em um primeiro momento, haveria uma tendência de rejeitar a ideia de indução de comportamentos no âmbito fiscal pelos relatos crescentes na mídia de casos de corrupção que rodeiam a atividade estatal e descredibilizam a função social arrecadatória dos tributos.

O modelo de análise de Kahneman (2012) baseia-se na divisão da mente humana em dois sistemas: sistema 1, responsável pela tomada de decisões de forma automática, mais instintivo; e sistema 2, mais concentrado e reflexivo. A avaliação acerca da viabilidade do uso de nudges no âmbito da cobrança de dívidas fiscais mereceria uma análise sobre o que o autor denominou de "sistema 2 da mente", ou seja, aquele que opera de forma mais reflexiva, e menos automática.

Não há dúvidas de que os interesses primários das partes são antagônicos no processo da cobrança de dívidas fiscais. O Estado Fiscal visa à arrecadação e os contribuintes sentem-se tolhidos na sua liberdade econômica diante do dever de pagar tributos. ${ }^{21}$

\section{Nudges fiscais: manipulação, transparência e o bem comum}

Uma das críticas mais comuns em relação ao uso de nudges em matéria tributária consiste no temor de que sua aplicação leve à manipulação indevida do comportamento dos cidadãos. Cogita-se acerca do seu potencial para influenciar as condutas de contribuintes por meio de mensagens subliminares, que não podem ser reveladas ao público.

Essas mensagens seriam diferentes das meras orientações em razão do seu caráter público. A aplicação do princípio da publicidade serviria como meio para monitorar o respeito às garantias e direitos individuais do contribuinte e inibir o governo de adotar medidas que não permitam uma defesa clara por parte da sociedade contra eventuais manipulações e induções (SUNSTEIN; THALER, 2019).

Como forma de reduzir esses riscos, tem-se ressaltado a importância da transparência no uso dos nudges e, dessa forma, de superar a barreira conflituosa entre o Estado e o contribuinte. De outro lado, Sunstein ${ }^{22}$ alerta que a transparência é importante, mas não é suficiente. É necessário que o objetivo seja legítimo.

Conforme visto, nudges visam ao incremento de objetivos socialmente desejáveis, ao bem-estar comum. Logo em seguida, surge a dúvida: o que seria esse bem-estar social na relação tributária? Nudges fiscais podem ter o fim exclusivamente arrecadatório?

Em que pese o dever fundamental do contribuinte de pagar tributo ${ }^{23}$ e a finalidade social da arrecadação, nudges fiscais devem considerar o interesse do cidadão, sob pena de ultrapassar o limite sugestivo para coação, sendo que a finalidade da intervenção é colaborativa e não fiscalizatória.

Preservada a liberdade de escolha do contribuinte e assegurada sua aplicação pública e transparente, considera-se que o bem comum perseguido pela implementação de nudges fiscais consiste em medidas que propiciem as melhores opções aos cidadãos ao mesmo tempo em que auxiliam no incremento da arrecadação. O indivíduo tem a liberdade de escolha preservada, que poderá ser induzida para fins que se adéquem não somente ao aumento da arrecadação, mas também à realização de escolhas inteligentes $\mathrm{e}$ menos danosas, financeiramente, ao contribuinte.

\footnotetext{
21 A relação tributária entre Estado e o cidadão é marcada permanentemente por conflitos, em parte fruto da herança história em que a soberania Estatal era exercida de forma impositiva, sem qualquer possibilidade de questionamento à semelhança de uma relação de escravidão. (MACHADO, 2018, p. 27).

22 Sunstein (2015, p. 429) faz importante ressalva: "There is a question whether transparency and public scrutiny are sufficient rather than merely necessary. The answer is that they are not sufficient. We could imagine forms of choice architecture that would be unacceptable even if they were fully transparent; consider (transparent) architecture designed to entrench inequality on the basis of sex. Here again, the problem is that the goals of the relevant nudge are illicit."

23 Adota-se o conceito mais genérico da palavra "tributo", sugerido por Marcelo Bufon (2009), e não a espécie "imposto", como exposto na obra clássica de Jose Casalta Nabais (2004).
} 
Um exemplo de busca do "bem comum" na relação tributária é o encaminhamento de lembretes de inadimplência fiscal, antes da adoção de providências judiciais mais gravosas, com proposições positivas de resolução da questão e indicação facilitada de acesso às informações. A medida alerta e minimiza o custo de quem apostou que não teria problemas com o Fisco ou mesmo de quem não tinha ciência das consequências ou possibilidades de resolução.

A propósito, Tipke (2012, p. 70-71) alerta que os agentes não têm que ser estimulados a arrecadar o máximo de tributos possível, como se isso fosse medida de um bom resultado. $O$ fazendário deve atuar como guardião do Direito Tributário, certo de que a finalidade arrecadatória do nudge fiscal atrela-se a uma política pública transparente e que possa ser defendida perante a sociedade.

Além disso, enfatiza-se que técnicas indutoras devem complementar um conjunto de medidas diversificadas de atuação do Fisco, visto que têm potencial com determinados perfis de comportamento de contribuintes, mas não com todos. Contribuintes que agem deliberadamente com o intuito de fraudar o Fisco não se sentem estimulados com pequenas intervenções. O comando e o controle intimidador continuam sendo opções. Cabe ao gestor público identificar quais intervenções são mais eficientes após análise do comportamento dos contribuintes. ${ }^{24}$

Ainda sobre o ambiente fiscal de implementação de nugdes, admite-se a necessidade de se aprimorar a forma como a administração tributária se relaciona com o cidadão para preservar a finalidade colaborativa da intervenção. O risco de desvirtuamento na indução de comportamentos minimiza-se quando o Estado Fiscal considera a importância de valorizar uma relação com o contribuinte que preza pela acessibilidade, transparência e diálogo. ${ }^{25}$

\section{Dos nudges fiscais aplicáveis}

A economia comportamental identificou vários vieses cognitivos que influenciam no comportamento do ser humano. Com fundamento nessas "falhas" mentais, vários países compreenderam a importância de implementar técnicas de nudges em suas políticas públicas, especialmente pelo baixo custo de investimento.

A Organização de Cooperação e Desenvolvimento Econômico (2017, p. 325-341) atestou resultados positivos de técnicas indutoras de comportamento, aplicadas no âmbito fiscal, em países como Canadá, Irlanda, Reino Unido e Nova Zelândia. Desde o encaminhamento de lembretes que reforçam normas sociais por meio de letras e gráficos coloridos a mensagens que incentivam o acesso a um cadastro de informações fiscais junto ao governo, a experiência internacional exitosa contribui para subsidiar a implementação de medidas parecidas, adaptáveis ao contexto da legislação tributária brasileira.

O sistema de cobrança da dívida ativa é território promissor para a aplicação de insights ${ }^{26}$ fiscais se consideradas algumas premissas: a) inércia dos devedores para adimplir dívidas fiscais; b) falta de conhecimento prévio do contribuinte sobre sua situação fiscal e sobre soluções possíveis para se regular; c) burocracia ao optar por se regularizar; d) aversão a pagar tributo pela perda financeira; d) influência social na decisão de pagar.

A inércia do devedor em pagar suas dívidas fiscais é explicada na "neuroeconomia" como resultado da aversão do indivíduo à perda financeira, mesmo quando for útil e lógico ao contribuinte se regularizar perante o Estado em algumas situações (SUNSTEIN; THALER, 2019, p. 45).

\footnotetext{
24 "Os gestores precisam entender quando tomar decisões formalmente, quando tomá-las seguindo a intuição e quando misturar as duas abordagens". (FOX, 2015, p. 65).

25 Considera-se ideal que administração busque uma margem de intervenção comunicativa que permita a discussão dos atores sociais envolvidos com vistas a definir as medidas a serem implementadas pelo Poder Público de forma que se crie um ambiente de estímulo com a existência de políticas públicas. (LIMA, 2013, p. 101).

26 Insights, na psicologia, são conceituados como a capacidade súbita de compreender sobre a verdadeira natureza de uma situação. (ABEL, 2003, p. 22-31).
} 
A aversão à perda consiste num viés que influencia na tomada de decisão e que pode não resultar nas melhores escolhas. Sunstein e Thaler $(2019$, p. 45) afirmam que a aversão à perda - desejo forte de conservar as posses atuais - produz inércia, porém "se você reluta em abrir mão do que possui porque não deseja perder, acaba rejeitando as trocas que teria feito numa situação diferente."

Somado a isso, estudos comprovam que, por diversas razões, há uma tendência das pessoas em se manterem em sua situação atual, fenômeno batizado de "viés do status quo". Uma das causas para esse fenômeno consiste na falta de atenção (SUNSTEIN; THALER, 2019, p. 46).

Portanto, é eficiente o Fisco que disponibiliza de maneira ágil a situação fiscal do contribuinte e alerta previamente sobre todas as condutas de cobrança a serem adotadas em caso de inadimplemento fiscal para evitar um otimismo irreal e recomendar medidas sensatas de prevenção antes da adoção de providências mais gravosas. Sunstein e Thaler (2019, p. 44) orientam que, "se são lembradas de um evento ruim, as pessoas podem diminuir o nível de otimismo".

Um exemplo viável de nudge fiscal é o lembrete encaminhado ao contribuinte informando sua inclusão em dívida ativa e todas as opções de regularização antes da adoção de medidas mais gravosas, que aumentam os encargos legais da dívida, como o protesto e o ajuizamento da respectiva execução fiscal.

Esse tipo de técnica pode ter efeito sobre grupo de devedores que se mantêm inertes diante da inadimplência, seja porque estavam mal informados sobre sua situação fiscal, seja porque sequer sabiam que eram devedores e quais as consequências da inadimplência.

Diferente da medida de protesto, em que há a notificação do devedor somente após a inclusão das custas cartorárias (medida de coação), esse tipo de insight alerta o contribuinte antes do ato. Logo, dá a liberdade de escolha ao devedor em se regularizar para evitar medidas que importem em mais perda financeira.

A Prefeitura de São Caetano do Sul adotou as premissas da economia comportamental e encaminhou notificações de pagamento de IPTU, do ano de 2019, com base no perfil do contribuinte, utilizando-se de um nudge fiscal (TUNES, 2019). Os que pagaram o imposto à vista no exercício de 2018 - cerca de 40,6\% dos contribuintes- receberam uma mensagem de agradecimento e estímulo pela atitude que permitiu à Prefeitura organizar melhor seus investimentos. Os que pagaram mensalmente (40,9\% dos moradores da cidade) também foram parabenizados, mas se ressaltou a possibilidade de pagamento à vista em 2019. Já aqueles que tinham uma ou mais parcelas em aberto $(7 \%)$ e os inadimplentes $(4,6 \%)$ foram esclarecidos de que a inadimplência pode levar ao protesto e à execução judicial dos débitos.

Além de lembretes constantes, facilitar o acesso à regularização de dívidas fiscais é um nudge simples, que visa ao interesse comum, mas encontra empecilhos em exigências burocráticas desnecessárias. Os cidadãos, mesmo com desagrado, podem até decidir adimplir suas obrigações fiscais, mas, se no meio do caminho, encontrarem algum empecilho de ordem burocrática, ou se não Ihe for facilitada a informação, podem ser levados pelo "viés do status quo" e deixar para outro momento, mesmo que isso possa lhe implicar prejuízos futuros. Isto porque "muitas pessoas aceitam a opção que exige o menor esforço - seja ela qual for - ou o caminho de menor resistência." (SUNSTEIN; THALER, 2019, p. 101).

Portanto, é salutar que as administrações tributárias estejam preparadas para atender de forma satisfatória os contribuintes que os procurem, facilitar o esclarecimento de dúvidas e investir em programas intuitivos, que simplifiquem o adimplemento de dividas, como por meio de sítios eletrônicos, de aplicativos, e, não menos relevante, capacitando os servidores fazendários para serem resolutivos e não procrastinadores quando demandados pelos contribuintes.

Enfatiza-se que a viabilidade de alguns insights depende da capacidade dos agentes fiscais em estarem preparados para o diálogo e serem proativos em interpretar a legislação e formular opções de negociação de dívidas fiscais, de modo a encontrar pontos de consenso que atendam à eficiência da arrecadação e ao interesse do contribuinte. 


\subsection{Insights no diálogo entre o fisco e o contribuinte}

No contexto de uma administração fiscal que persegue a eficiência, ${ }^{27}$ é necessário, essencialmente, que seus agentes estejam capacitados a dialogar, a negociar, a ouvir os contribuintes. Em conciliações, algumas técnicas de nudge podem se mostrar úteis no convencimento para se firmar um acordo.

A técnica de enquadramento se refere à forma de se abordar a questão. Trata-se de um insight simples, mas que funciona, porque a maioria das pessoas tende a tomar decisões de forma desatenta e passiva, sem se atentar que as respostas poderiam ser diferentes caso a forma de questionar fosse outra. Apresentar o problema de maneira empática, por exemplo, pode influenciar na disposição do contribuinte, porque "as decisões dependem, em parte, da forma como os problemas são apresentados" (CAVALCANTE; FERNANDES, 2018, p. 48).

Ancoragens consistem em técnicas de nudge realizadas por meio da inserção de um ponto de partida para o processo de desenvolvimento do pensamento, pois "evidências mostram que, dentro de um limite razoável, quando mais se pede, mais se obtém”. Os melhores negociadores costumam fazer uma proposta inicial tão elevada que a outra parte, ao final, fica satisfeita em pagar apenas metade do proposto (SUNSTEIN; THALER, 2019, p. 35).

É importante, nesse sentido, que a legislação fiscal propicie escolhas ou alternativas de decisão ao contribuinte para regularizar sua situação fiscal ${ }^{28} \mathrm{~A}$ arquitetura de escolhas pressupõe que existem alternativas e não somente uma única opção. A técnica de ancoragem funciona se existirem alternativas a serem propostas.

A título de exemplo, poder-se-ia citar a oferta de opções de pagamento de dívidas fiscais além do simples parcelamento, como a previsão de período de carência, recebimento de bens como parte de pagamento, ou dispensa de garantia a depender do histórico fiscal do contribuinte.

Já a técnica de mapeamento consiste em fazer com que o outro visualize as correlações entre as escolhas e consequências. Nesse sentido, "um bom sistema de arquitetura de escolhas ajuda as pessoas a melhorar a própria capacidade de fazer o mapeamento correto, e com isso escolher as alternativas mais benéficas para si". (SUNSTEIN; THALER, 2019, p. 109).

Sunstein e Thaler (2019, p. 116) ressaltam, ainda, que "bons arquitetos de escolhas podem direcionar a atenção das pessoas para os incentivos". Portanto, é interessante que o agente do fisco dê visibilidade aos benefícios que poderão ser atingidos caso o contribuinte regularize suas dívidas.

Os advogados fazendários, portanto, são potenciais arquitetos de escolhas, responsáveis por organizar todo o contexto do diálogo com o contribuinte, podendo utilizar técnicas como enquadramento e ancoragem, e deixar evidente todas as opções possíveis na legislação para resolver o litígio (mapeamento). Ressaltariam, ainda, os benefícios disponíveis e o que os outros contribuintes fizeram em relação ao mesmo assunto (influência social).

Sunstein e Thaler (2019, p. 255) alertam que o agente público incompetente, ou que age em benefício próprio, não está apto a implementar nudges. A técnica indutora mostra-se legítima desde que o influenciador seja capacitado. Esse é o ponto mais crítico do estudo, porque o risco de se admitir a possibilidade de medidas de indução pelo Estado Fiscal não está no modo, e sim em quem irá adotar essas técnicas.

Esse risco é inerente a toda medida adotada pelo Estado, porque o exercício estatal é delegado a humanos. Basta imaginar, por exemplo, que a tecnologia é um instrumento que traz benefícios, mas pode ser ferramenta de opressão e ferir afrontosamente garantias individuais, a depender das intenções de quem

27 Denise Lucena e André Dias, ao tratar do conceito de administração fiscal dialógica, concluem que, enquanto não se chega ao ponto ideal da adequação da legislação tributária, a criação de um diálogo institucionalizado entre o Fisco e contribuinte poderá ser um instrumento eficaz em busca das boas práticas. (CAVALCANTE; FERNANDES, 2018).

28 Quando as instituições de caridade pedem uma doação, costumam apresentar mais de uma opção de valor: 100 (cem) dólares, 250 (duzentos e cinquenta) dólares, 5 (cinco) mil ou outro, "esses valores não são aleatórios, porque as opções influenciam o valor que as pessoas decidem doar”. (SUNSTEIN; THALER, 2019, p. 35). 
administra (HARARI, 2018, p. 15). Mas essa ameaça não se revela suficiente para afastar a necessidade do uso da tecnologia pelo Estado Fiscal em busca do aprimoramento dos seus serviços e resultados.

\subsection{Influência social e conduta padrão}

A teoria econômica comportamental garante que a influência social condiciona profundamente a decisão das pessoas. O chamado "efeito manada" resulta de decisões tomadas com base no padrão comportamental coletivo.

As influências sociais se agrupam em duas categorias básicas. A primeira envolve informações. Se muitas pessoas fazem ou pensam algo, suas ações e pensamentos transmitem informações o que seria mais conveniente fazer ou pensar. A segunda envolve pressão social. Se você se importa com que os outros pensam a respeito. (SUNSTEIN; THALER, 2019, p. 67).

Alguns grupos de indivíduos são influenciados pelo fenômeno do "conservadorismo coletivo", entendido como a tendência das pessoas se manterem num determinado padrão de conduta mesmo quando cientes da necessidade de se comportarem de outra forma. Nessa perspectiva, "somos capazes de adotar uma prática ou seguir uma tradição não porque gostamos, ou mesmo porque a consideramos defensável, mas basicamente porque achamos que a maioria das pessoas aprova" (SUNSTEIN; THALER, 2019, p. 71).

O "efeito manada" considerado pela economia moderna ajuda a compreender porque alguns grupos de devedores não se incomodam com dívidas fiscais como se incomodariam se tivessem o cartão de crédito bloqueado por estarem inadimplentes com instituições financeiras privadas.

Um marcante discurso social sobre a má gestão dos recursos públicos, a alta carga tributária, a precariedade de serviços ofertados aos cidadãos, entre outros aspectos negativos, contribuem com a percepção da "legitimidade e da aceitação coletiva da sonegação, como se essa conduta fosse o 'padrão dos cidadãos'".

Klaus Tipke (2012, p. 114) sugere um intenso trabalho de marketing para influenciar a convicção da sociedade de que o agir moral fiscal do cidadão é um dever cívico em prol da coletividade, e não um esporte nacional clandestino, porém amplamente aceito socialmente.

James Alm e Martinez-Vazquez (2007, p. 51), ao analisarem o comportamento dos contribuintes na América Latina e Caribe, confirmam que "such an outcome is common in many countries, such as those in the LAC region, where it seems to be accepted that tax evasion is the norm." 29

De outro lado, utilizando-se da "heurística da disponibilidade", ${ }^{30}$ se o Fisco conferir visibilidade a condutas positivas de contribuintes que procuram cumprir com suas obrigações fiscais, a referida medida pode impulsionar uma conduta padrão mais propensa à cidadania fiscal.

Confere-se visibilidade à conduta padrão positiva de contribuintes com o fim de induzir comportamentos em massa voltados à regularização de dívidas fiscais, porque os cidadãos, "quando recebem a informação de que o nível de cumprimento da lei é alto, eles se tornam menos propensos a burlar o fisco". (SUNSTEIN; THALER, 2019, p. 80).

Interessa às pessoas saber o que os outros estão fazendo, de modo que se torna possível estimular comportamentos, até certa medida, apenas publicizando as ações de outros contribuintes que se encontravam na mesma situação (SUNSTEIN; THALER, 2019, p. 80). Portanto, é possível induzir condutas por meio da ênfase e da repetição de informações estatísticas positivas (SUNSTEIN; THALER, 2019, p. 82).

Sunstein e Thaler (2019, p. 80) narram o seguinte experimento que comprova como a influência social é um insight poderoso:

\footnotetext{
29 Tradução livre: "Tal conclusão é comum em muitos países, como nesses da América Latina e Caribe, onde parece ser aceito que evasão tributária é a norma."

30 "Avalia-se o risco de algo acontecer de acordo com a facilidade com que conseguem pensar na questão” (SUNSTEIN; THALER, 2019, p. 35).
} 
[...] contribuintes receberam quatro tipos de informação. Um deles ficou sabendo que seus impostos eram destinados a boas causas, como educação [...]. Outros sofreram ameaça com informações sobre os riscos de punição [...]. Outro grupo foi instruído sobre como obter ajuda caso tivessem dúvidas ou dificuldades para preencher formulários. E, por fim, um grupo recebeu a informação de que mais de $90 \%$ dos moradores [...] pagavam impostos e estavam em dia com o fisco. Só uma dessas intervenções exerceu um efeito significativo: a última. Ao que parece, alguns contribuintes eram mais propensos a descumprir a lei devido a uma percepção equivocada - plausivelmente baseada no grande número de relatos de sonegação fiscal veiculado por meios de comunicação ou por outros modos - de que o percentual de cidadãos cumpridores da lei é bastante baixo.

Facilitar o parcelamento de dívidas fiscais atreladas a mensagens indicativas do nível de conformidade dos demais contribuintes (repare: quando você reserva um hotel pelo site sempre há um indicativo de quantas pessoas estão visualizando exatamente o hotel que você está em dúvida em reservar), é um exemplo potencial de nudge fiscal que pode gerar resultados positivos, porque alerta sobre os que os outros estão fazendo.

\subsection{Nudges fiscais que visam à conformidade por meio de incentivos}

Diferenciar contribuintes com base em requisitos objetivos - e transparentes - também pode ser um insight fiscal eficiente baseado nas constatações da economia comportamental de que a influência social é considerada um elemento relevante na decisão de contribuintes em pagar tributo.

Não por acaso, as administrações tributárias têm investido em medidas de nudge para estimular o pagamento de tributos. Com base em recomendações da $\operatorname{OCDE}(2014$, p.19) procura-se orientar a atuação fiscal de modo a tratar de maneira diferente contribuintes com padrões distintos de comportamento em face do Fisco.

Leis tributárias já autorizam que contribuintes sejam classificados em notas conforme histórico fiscal, e os mais confiáveis são indicados como contribuintes "nota A", "regulares", "legais", em contraposição aos considerados "sonegadores" ou apontados como "devedores contumazes". ${ }^{31}$

A tendência é que aqueles que não se encaixem na conduta padrão de contribuinte "nota A" se esforcem e se sintam estimulados para isso pelo fenômeno da conformidade. Sunstein (2019, p. 5-7) explica que dois fatores influem no comportamento humano: o primeiro envolve as informações transmitidas pelas decisões de outras pessoas. Se muitas pessoas acreditam em uma proposta, isso seria motivo para se confiar em sua veracidade. As pessoas tendem a "seguir a multidão". O segundo fator seria o desejo do ser humano de ser aceito pelos outros, ou seja, a discordância surge como situação menos comum ou atípica.

Objetiva-se, portanto, com o tratamento diferenciado, implementar uma política fiscal de incentivos e punições considerando o perfil de comportamento de cada contribuinte, para adequar a lei àqueles que se esforçam no cumprimento das suas obrigações fiscais. O reforço dos comportamentos positivos viria acompanhado da deslegitimação da sonegação e sua caracterização como uma conduta desviante e excepcional. ${ }^{32}$

De todo modo, incentivos baseados no reconhecimento social do cidadão têm efeitos reconhecidos (MACHADO SEGUNDO, 2018, p. 653). Essa contraposição entre o "bom" e o "mau" interfere na decisão do contribuinte por meio da pressão social e investe na visibilidade da conduta padrão do bom contribuinte, já que apenas a minoria dos devedores tem perfil criminoso.

Os econos reagem, acima de tudo, a incentivos. Se o governo começar a tarifar doces, eles passam a comprar menos, mas são influenciados por fatores 'irrelevantes' como a ordem em que as opções

31 A Lei Complementar n. ${ }^{\circ} 1320$, de abril de 2018, do estado do São Paulo foi a primeira a trazer elementos de diferenciação de contribuintes com o fim de estimular a conformidade tributária. Em outra ponta, o projeto de lei $n .^{\circ} 1646$ de 2019 estabelece medidas para o combate ao devedor contumaz que prejudica a livre concorrência pela inadimplência reiterada e substancial no recolhimento de tributos.

32 James Alm e Martinez-Vazquez (2007, p. 51) alertam, no entanto, que anistias fiscais não conduzem à conformidade tributária: "The introduction of a tax amnesty may also affec the social norm of compliance. A tax amnesty gives individuals an opportunity to pay previously unpaid back taxes without being subject to the penalties that the discovery of evasion normally brings. Such amnesties may reduce compliance if honest taxpayers resent the tax forgiveness given to o tax cheats (and if individuals believe that the amnesty may be repeated again)". 
são exibidas. Humanos também reagem a incentivos, mas sofrem forte influência dos nudges. Ao implantar adequadamente tanto incentivos quanto nudges, aumentamos a nossa capacidade de melhorar a vida das pessoas e ajudamos a resolver muitos dos problemas da sociedade. $E$ tudo isso sem impedir a liberdade de escolha do indivíduo. (SUNSTEIN; THALER, 2019, p. 17).

Interessante, nessa ordem de ideias, o estudo de Samuel Bowles que sugere diretrizes e ressalvas à política de influenciar as decisões de cidadãos por meio de incentivos e sanções.

Bowles (2016, p. 3) destaca que os incentivos e punições podem ter efeito contrário ao pretendido se formulados a cidadãos considerados conforme o paradigma da economia clássica, ou seja, que se interessam apenas em ganhos perdas:

The problem facing the policy maker or constitution writer is this: incentives and constraints are essential to any system of governance. But when designed as if "men they are" resemble Homo economicus, incentives might backfire if they foster the very self-interest that they were designed to harness in the service of public good. ${ }^{33}$

$\mathrm{Na}$ sua pesquisa, o autor relata evidências de que existem outros fatores éticos e psicológicos delineadores do comportamento do cidadão, e demonstra o resultado de incentivos e punições em algumas situações. ${ }^{34} \mathrm{O}$ pesquisador faz referência aos resultados encontrados quando crianças eram incentivadas a ajudar terceiros pela possibilidade de ganhar brinquedos. Bowles $(2016$, p. 5$)$ atesta que a premiação diminuiu em quarenta por cento a inclinação natural que as crianças possuem de ajudar os outros.

No mesmo sentido, a multa pecuniária aplicada por uma creche em Israel pelo atraso dos pais em buscar seus filhos no horário teve o efeito contrário: os atrasos passaram a ser mais frequentes. Incentivos ou restrições funcionam como mensagens aos seus destinatários que se atentam ao propósito e motivos dessa política de recompensas. No exemplo acima, Bowles (2016, p. 4) constata que a multa, ao invés de inibir, deu o conforto mental ético necessário aos pais em saber que podiam praticar tal conduta, desde que pagassem.

Ademais, quando se entende o estímulo como forma de controle, a medida tende a tornar-se ineficaz (BOWLES, 2016, p. 97). Em experimento citado por Bowles (2016, p. 99) para incentivar crianças a desenhar mediante recompensa atestou que não foi o prêmio em si que afetou negativamente o interesse das crianças, e sim a sensação de controle e o comprometimento da autonomia.

A supervisão rigorosa de uma atividade essencialmente espontânea pode ser tão prejudicial quanto um sistema de incentivos e restrições baseado no interesse material dos indivíduos (BOWLES, 2016, p. 99). Esse resultado é interessante para o objeto do presente estudo, porque fundamenta a medida de diferenciar contribuintes para evitar a fiscalização excessiva desnecessária sobre aqueles que não apresentam maior propensão à sonegação de impostos.

As conclusões de Bowles contribuem para fundamentar uma política fiscal que considere que múltiplos fatores influem no comportamento do contribuinte; e que não são exclusivamente econômicos. Portanto, colocar preço em tudo ou trabalhar apenas com incentivos financeiros (negativos e positivos) não é a melhor solução, pois, em algumas situações, leva à depreciação de valores éticos e morais pré-existentes, ou à corrosão precoce da boa vontade do cidadão (BOWLES, 2016, p. 5, 79).

A diferenciação de contribuintes pode ser um incentivo eficaz desde que a administração tributária considere, em conjunto, os interesses econômicos somados a elementos morais, sociais, culturais e psicológicos que influenciem a conduta do indivíduo. Na implantação de normas de recompensa, devese evitar o desengajamento moral em relação ao dever fundamental de pagar tributos e a provocação no contribuinte de aversão ao controle estatal.

\footnotetext{
33 Tradução livre: O problema enfrentado pelos elaboradores das políticas públicas ou redatores da constituição é que: incentivos e restrições são essenciais para qualquer sistema de governança. Mas quando desenhado como se os homens fossem semelhantes ao Homo economicus, os incentivos podem ter efeito contrário se eles promoverem exatamente o autointeresse que eles deveriam domar no interesse do bem comum.

34 "But over the past two decades, behavioral experiements (as we see in chapters III, IV, and V) have provided hard evidence that ethical and other - regarding motives are commom in virtually all human population" (BOWLES, 2016, p. 3).
} 
Consistente com a ideia de que incentivos e restrições podem ser eficazes a depender da mensagem que transmitem aos seus destinatários, ${ }^{35}$ a diferenciação de contribuintes pode ser um nudge fiscal eficaz, desde que a ideia a ser reafirmada ao contribuinte seja de confiança, e não exclusivamente de ganho financeiro ou controle.

Na legislação tributária, por exemplo, observa-se com frequência a exigência de garantia para parcelamentos de dívidas fiscais com o fim de assegurar a expropriação de bens em caso de rescisão. Mas se o parcelamento fiscal já importa em confissão de dívida pelo devedor e desistência de discutir a exigência com a perspectiva de aumento imediato da arrecadação, por que exigir garantia daqueles contribuintes que, historicamente, não têm o perfil de rescindir parcelamentos?

A mensagem que se transmite ao conceder parcelamento sem garantia para determinados contribuintes - recompensa - é de que o Estado Fiscal não tem motivos para desconfiar de quem sempre adimpliu com parcelamentos anteriores. Mostrar-se-ia desproporcional a exigência adicional de um ônus para quem está predisposto a confessar sua dívida e apresenta um histórico fiscal de adimplência regular de parcelamentos anteriores.

Recompensar determinados contribuintes com avaliação mais rápida de documentos apresentados em pedidos administrativos, por exemplo, na análise de bens imóveis apresentados para garantir a execução fiscal, ou no preenchimento de determinados requisitos para ser restituído pelo pagamento a maior de tributos, podem transmitir a mensagem de que não é necessária uma fiscalização rigorosa sobre quem não tem, em seu histórico, conduta fraudulenta ou prática de sonegação fiscal.

Em contraposição, incentivar ou sancionar contribuintes com fundamento exclusivo em quem paga mais imposto ou, exclusivamente, na conduta de inadimplência pode ter efeito adverso na arrecadação, porque pode transmitir a mensagem de que o Fisco só considera cidadão quem tem poder econômico.

\section{Conclusão}

Os nudges podem ter aplicação na relação tributária do contribuinte com o Fisco, desde que a administração tributária seja acessível, transparente e disponibilize ferramentas de monitoramento de sua atuação com o fim preservar a liberdade de escolha do cidadão e evitar o desvirtuamento da medida.

O Fisco que pretende investir no diálogo e na negociação com o contribuinte deve considerar capacitar seus agentes para esse tipo de medida, pois a conciliação pressupõe uma relação horizontal entre as partes, a capacidade de escutar ativamente o cidadão e a noção de que o Fazendário deve ser resolutivo e atender à legislação, mesmo quando isso se contrapuser ao objetivo de ampliar a arrecadação. Somente nesse contexto revela-se segura a utilização de nudges fiscais pelo Estado e evita-se a indução de negociações que visem, exclusivamente, ao aumento de receita.

Finalmente, considera-se que os resultados encontrados pela teoria da economia comportamental fundamentam os efeitos de algumas técnicas de nudges na tomada de decisões de determinados perfis de contribuintes, de modo que o nudge se revela uma medida promissora, de baixo custo, sem excluir outras, para aprimorar os resultados da arrecadação fiscal.

\section{Referências}

ABEL, Marcos Chedid. O insight na psicanálise. Psicologia Ciência e Profissão, Brasília, v. 23, n. 4, p. 22-31, 2003. Disponível em: http://www.scielo.br/pdf/pcp/v23n4/v23n4a05.pdf. Acesso em: 30 out. 2019.

\footnotetext{
35 Bowles (2016, p. 79) traz o exemplo de duas empresas que adotaram políticas de segurança diferentes em relação aos seus empregados. A primeira, para evitar o desaparecimento de ferramentas na fábrica, determinou que essas fossem trancadas no final do expediente. A mensagem passada foi de desconfiança, portanto, os resultados não foram eficazes. Diferentemente de outra empresa, na qual os empregados foram incentivados a levarem as ferramentas para casa. Além de transmitir a ideia de confiança, induziu o trabalho em casa.
} 
ALLINGHAM, M. G.; SANDMO, A. Income tax evasion: a theoretical analysis. Journal of Public Economics, v. 1, p. 323-338, 1972. Disponível em: http://www3.nccu.edu.tw/ klueng/tax\%20paper/1.pdf. Acesso em: 24 nov. 2019.

ALM, James; MARTINEZ-VAZQUEZ, Jorge. Tax morale and tax Evasion in Latin America (Working Paper 07-04). Atlanta: Georgia State University, 2007. Disponível em: https://icepp.gsu.edu/files/2015/03/ ispwp0732.pdf Acesso em: 30 out. 2019.

BIRD, Richard. Smart tax administration. Economic Premise, Washington, n. 36, out. 2010. Disponível em: http://documents. worldbank.org/curated/en/281951468162555914/pdf/573980BRIOEP360Box35374 7B01PUBLIC1.pdf. Acesso em: 24 nov. 2019.

BOWLES, Samuel. The moral economy: why good incentives are no substitute for good citizens. New Haven: Yale University Press, 2016.

BRASIL. Supremo Tribunal Federal. Recurso extraordinário $n^{\circ}$ 833.106. Relator: Min. Marco Aurélio, 12 de dezembro de 2014. Disponível em: http://portal.stf.jus.br/processos/detalhe.asp?incidente=4623266. Acesso em: 21 nov. 2019.

BUFFON, Marciano. Tributação e dignidade da pessoa humana: entre direitos e deveres fundamentais. Porto Alegre: Livraria do Advogado, 2009.

CASALTA NABAIS, José. O dever fundamental de pagar impostos. Coimbra: Almedina, 2004.

CAVALCANTE, Denise Lucena; FERNANDES, André Dias. Administração fiscal dialógica. Revista de Direito Administrativo, Rio de Janeiro, v. 277, p. 40-70, 2018.

FERGUSIN, Andrew. Nudge nudge, wink wink. Washington Examiner, abr. 2010. Disponível em: https:// www.washingtonexaminer.com/weekly-standard/nudge-nudge-wink-wink. Acesso em: 25 out. 2019.

FOX, Justin. Do "homem econômico" à economia comportamental. Harvard Business Review, v. 93, n. 5, 2015.

HARARI, Yuval Noah. 21 lições para o século 21. São Paulo: Companhia das Letras, 2018.

KAHNEMAN, Daniel; TVERSKY, Amos. Judgement under uncertainty: heuristics and biases. Science, [S.I], v. 185, n. 4157, p. 1124-1131, 1974. Disponível em: https://www.its.caltech.edu/ camerer/Ec101/ JudgementUncertainty.pdf. Acesso em: 24 nov. 2019.

KAHNEMAN, Daniel. Rápido e devagar: duas formas de pensar. Rio de Janeiro: Objetiva, 2012.

KOROBKIN, Russel B.; ULEN, Thomas S. Law and law and behavioral science: removing rationality assumption from law and economics. California Law Review, v. 88, p. 1138-1144, 2000. Disponível em: https://scholarship.law.berkeley.edu/cgi/viewcontent.cgi?article=1490\&context=californialawreview. Acesso em: 24 nov. 2019.

LIMA, Raimundo Márcio Ribeiro. Administração pública dialógica. Curitiba: Juruá, 2013.

MACHADO, Hugo de Brito. Curso de direito tributário. 39. ed. São Paulo: Malheiros, 2018.

MACHADO SEGUNDO, Hugo de Brito. Ciência do direito tributário, economia comportamental e extrafiscalidade. Revista Brasileira de Políticas Públicas, Brasília, v. 8, n. 2, p. 639-659, 2018.

ORGANISATION FOR ECONOMIC CO-OPERATION AND DEVELOPMENT. Measures of Tax

Compliance Outcomes: A practical guide. OECD Publishing, 2014. Disponível em: http://www.oecd.org/ tax/administration/measures-of-tax-compliance-outcomes-9789264223233-en.htm. Acesso em: 24 nov. 2019.

ORGANISATION FOR ECONOMIC CO-OPERATION AND DEVELOPMENT. Behavioural insights and public policy: Lessons from Around World. OECD Publishing, Paris, 2017. Disponível em: https://read. oecd-ilibrary.org/governance/behavioural-insights-and-public-policy_9789264270480-en\#page. Acesso em: 25 out. 2019.

RIBEIRO, Maria Carla Pereira; DOMINGUES, Victor Hugo. Economia comportamental e direito: a racionalidade em mudança. Revista Brasileira de Políticas Públicas, Brasília, v. 8, n. 2, 2018. 
SUNSTEIN, Cass R. Conformity: the power of social influences. New York: New York University Press, 2019.

SUNSTEIN, Cass; THALER, Richard H. Nudge: Como tomar melhores decisões sobre saúde, dinheiro e felicidade. Rio de Janeiro: Objetiva, 2019.

SUNSTEIN, Cass. Why nudge? the politics of libertarian paternalism. Londres: Yale University Press, 2012.

SUNSTEIN, Cass. The ethics of nudging. Yale Journal on Regulation, v. 32, 2015. Disponível em: http://digitalcommons.law.yale.edu/yjreg/vol32/iss2/6. Acesso em: 24 nov. 2019.

THALER, Richard H. Misbehaving: a construção da economia comportamental. Rio de Janeiro: Intríseca, 2015.

THE BEHAVIOURAL INSIGHTS TEAM. Annual Report 2017-18. London: BIT, 2018. Disponível em: https://www.bi.team/wp-content/uploads/2019/01/Annual-update-report-BIT-2017-2018.pdf. Acesso em: 19 nov. 2019.

TIPKE, Klaus. Moral tributária do Estado e dos contribuintes. Porto Alegre: Sérgio Antonio Fabris, 2012.

TORRES, Ricardo Lobo. Liberdade, consentimento e princípios de legitimação do direito tributário.

Revista Internacional de Direito Tributário, Belo Horizonte, v. 5. n. 1, p. 223-244, 2006.

TUNES, Suzel. São Caetano do Sul adota economia comportamental para elevar eficiência no IPTU. Prefeitura Municipal de São Caetano do Sul, São Caetano do Sul, mar. 2019. Disponível em: http:// www.saocaetanodosul.sp.gov.br/noticias-scs/sao-caetano-do-sul-adota-economia-comportamental-paraelevar-eficiencia-no-iptu.html. Acesso em: 25 out. 2019.

Autores convidados. 